\title{
A STUDY OF BODY CAVITY EFFUSIONS AND ITS DIAGNOSTIC UTILITY OF CELL BLOCK AS AN ADJUNCT TO CONVENTIONAL CYTOLOGICAL SMEARS
}

\section{Medical Science}

Dr. Ankan Nandi* Senior Resident, Nandigram Superspeciality Hospital. *Corresponding Author

Dr. Debarshi Jana IPGMER And SSKM Hospital, Kolkata, WB.

\section{ABSTRACT}

BACKGROUND: The cell block technique is one of the oldest method for evaluation of body cavity fluids and it increases the sensitivity of the diagnosis in comparison to conventional smear study. The main advantage of cell block technique is preservation of tissue architecture and obtaining multiple sections for special stains. AIM: To assess the utility of cell block method in increasing the sensitivity of cytological diagnosis of body cavity effusions as an adjunct to conventional smear method. MATERIAL AND METHODS: It was institution based cross sectional observational study. All patients presenting with effusion and those who was give consent for participating in the study was included in this study. The study was conducted in Dept. Of Pathology, Nandigram Superspeciality Hospital. 100 cases fulfilling the predetermined inclusion and exclusion criteria was taken during the study period. RESULT: Association of Cellularity vs cell block was statistically significant ( $<<0.0001$ ). Association of Architectural Pattern vs cell block was not statistically significant $(\mathrm{p}=0.7883)$. Association of cytological smears vs cell block was statistically significant $(\mathrm{p}=<0.0001)$. CONCLUSION: Cell block technique is superior to conventional smear technique, especially for malignant effusions.

\section{KEYWORDS}

Cell Block, Conventional Cytological Smears, Body Cavity Effusions, Architectural Pattern.

\section{INTRODUCTION}

An accumulation of fluid other than blood in body cavity called an effusion which result from an imbalance of fluid production and reabsorption. In the pleural, pericardial and peritoneal cavities, this acumulation is known as serous effusions. There are two types of effusion-Transudate and Exudate. The cytological examination of serous fluid is important in the diagnosis, staging and prognosis of malignant lesions. In conventional cytological smear accurate identification of reactive mesothelial cells, mesothelioma and malignant cells is a diagnostic problem.

Cytological examination of serous fluids is one of the commonly performed investigation. The accurate identification of cells as either malignant or reactive mesothelial cells is a diagnostic problem in conventional cytological smears. The cell block (CB) technique is one of the oldest methods for the evaluation of body cavity fluids ${ }^{1}$. The main advantages of the $\mathrm{CB}$ technique are preservation of tissue architecture and obtaining multiple sections for special stains and immunohistochemistry. ${ }^{2}$

Cytological study of body fluid is a complete diagnostic modality. The information provided by cytological analysis serves several functions. First, it helps the clinician in pointing out and formulating the cause of effusion and list of differential diagnoses and also helps in therapy \& prognosis of patient.

The accurate identification of cells as either malignant or reactive mesothelial cells is a diagnostic problem in conventional cytological smears. Distinguishing benign from malignant cellular changes may require thorough screening, careful scrutiny of cellular architecture and evaluation of the range of reactive changes. Due to artifact, cellular overlapping suboptimal preparation \& processing causes lower diagnostic yield in CS method. . The cell block (CB) technique is one of the oldest and complementary methods for the evaluation of body cavity fluids ${ }^{1}$. Cell block preparation increases the sensitivity of detecting malignancies and reduce false-positive interpretations. This method is simple and inexpensive which requires no extra material compared to other methods. The main advantages of the CB technique are preservation of tissue architecture and obtaining multiple sections for special stains and immunohistochemistry ${ }^{2}$. Cell blocks are helpful in situations where the cytological abnormalities are ambigious like in reactive mesothelial cells, mesothelioma or in occasional well differentiated adenocarcinoma Apart from increased cellularity,better morphological details are obtained by cell block method as there is a better conservation of architecture features like arrangement of cells, cytoplasmic and nuclear details.

i. To assess the utility of cell block method in increasing the sensitivity of cytological diagnosis of body cavity effusions as an adjunct to conventional smear method.

\section{METHODOLOGY}

a) Study design

It was institution based cross sectional observational study.

All patients presenting with effusion and those who was give consent for participating in the study was included in this study. Detailed history and clinical examination was done .Aspirated fluid was subjected to both conventional smear study \& cell block study and the utility of cell block method as an adjunct to conventional smear method was evaluated.

\section{b) Study setting and timelines}

The study was conducted in Dept. of Pathology, Nandigram Superspeciality Hospital.

\section{f)Sample size}

100 cases fulfilling the predetermined inclusion and exclusion criteria was taken during the study period.

\section{h) Inclusion criteria}

The serous effusion samples of pleural,peritoneal\& pericardial cavity obtained from both male and female of age groups.

\section{Exclusion criteria}

1)CSF

2)Fluid from cystic lesion

3)Synovial fluid

4)Inadequate sample volume(less than $15 \mathrm{ml}$ ).

\section{i) Study variables:}

i) Case record form

ii) Informed consent form

iii) Clinical history; includes patient particulars, chiefcomplaint,contanct numbers.

iv) Available laboratory investigation report

v) Tools \& stains for conventional stain technique i.e, Papanicolaousstain(PAP),Leishman-Giemsa(LG)stain,

vi) Tools for cell block technique

vii) Microscope

viii) Books, articles, journals relevant to the topic of study.

\section{6) Statistical analysis}

Through tabulation of data ,graphical depiction using appropriate charts and tables and with appropriate statistical methods.

\section{RESULT AND DISCUSSION}

Dey $S$ et al $^{3}(2017)$ found that maximum patients belonged to the age group of 61-70 years. Male:female ratio 1:1.17. Most common cause of malignant peritoneal effusion was due to ovarian malignancies in females. Sensitivity and specificity of CB compared to conventional 
smear were $88.88 \%$ and $86.98 \%$, respectively. CB produced significantly better results $(\mathrm{P}=0.0271)$ while detecting malignant lesions and reducing suspicious results $(\mathrm{P}=0.0226)$.

Sudha A et al $^{4}$ (2018) found that out of 302 cases, pleural fluids, 148 $(49.0 \%)$ cases, were most common, followed by peritoneal fluid, 125 $(41.39 \%)$ cases and least common was pericardial fluid, 8 (2.64\%) cases. The maximum numbers of cases was in 5th decade. The age range was 3 years to 84 years. Female preponderance was observed with M: F ratio of 1: 1.17.

It was found that association of age in years vs cell block was not statistically significant $(\mathrm{p}=0.9035)$. Association of SEX vs cell block was statistically significant $(\mathrm{p}=0.3246)$.

Barui $\mathbf{G}$ et $\mathbf{a l}^{5}$ (2017) found that diagnoses obtained by CS and CB method were statistically analysed. ere pleural fluid, 24 ascitic fluid and 7 pericardial fluids. 9 cases in pleural flu Out of total 115 fluid samples, 84 wid and 6 cases in ascitic fluid were false-negative by CS, which were proved to be malignant by $\mathrm{CB}$ method. So, additional $13.1 \%$ yield were obtained by $\mathrm{CB}$ method to diagnose malignant cases.

We found that in Benign, 23(34.3\%) patients had Ascitic Fluid, 4(6.0\%) patients had Pericardial Fluid and 40(59.7\%) patients had Pleural Fluid.In Malignant, 13(40.6\%) patients had Ascitic Fluid and 19(59.4\%) patients had Pleural Fluid. In Suspicious, 1(100.0\%) patients had Pleural Fluid.Association of Fluid vs cell block was not statistically significant $(\mathrm{p}=0.5846)$

Kumavat PV et al ${ }^{6}$ (2013) found that out of 550, 315 were pleural effusions, 234 peritoneal and one was pericardial. Out of total 315 cases of pleural effusions, 297 were non neoplastic and 18 were neoplastic effusion. Out of total 234 peritoneal effusions 214 were non neoplastic and 20 neoplatic. Commonest malignancy in pleural and peritoneal fluid was adenocarcinoma. Conclusion: Pleural effusion was the commonest fluid in this study.

It was found that in Benign, 24(34.8\%) patients had Ascitic Fluid, $4(5.8 \%)$ patients had Pericardial Fluid and $41(59.4 \%)$ patients had Pleural Fluid.In Malignant, 8(36.4\%) patients had Ascitic Fluid and 14(63.6\%) patients had Pleural Fluid.In Suspicious, 4(44.4\%) patients had Ascitic Fluid and 5(55.6\%) patients had Pleural Fluid.Association of Fluid vscytological smearswas not statistically significant $(\mathrm{p}=0.7198)$.

Shivakumarswamy $\mathbf{U}$ et al $^{7}$ (2012) found that Statistical analysis with the ' $z$ test' was performed to identify the cellularity, using the CS and CB methods. Mc. Naemer's $\chi 2$ test was used to identify the additional yield for malignancy by the $\mathrm{CB}$ method. Cellularity and additional yield for malignancy was $15 \%$ more by the $\mathrm{CB}$ method.

Suri $\mathbf{J}$ et al ${ }^{8}(\mathbf{2 0 1 5})$ found that cell block technique is superior to conventional smear technique, especially for malignant effusions.

Matreja SS et al ${ }^{9}$ (2017) found that CB method provided higher cellularity, better architectural patterns and additional yield for malignancy as compared to $\mathrm{CS}$ method $(\mathrm{P}<0.005)$. Itis advisable to routinely make $\mathrm{CBs}$ before discarding specimens that are suspicious for malignancy by smear examination.

In benign, $67(97.1 \%)$ patients were benign and 2(2.9\%) patients were malignant. In malignant, $22(100.0 \%)$ patients were malignant.In suspicious, $8(88.9 \%)$ patients were malignant and $1(11.1 \%)$ patients were suspicious.Association of cell blockvs cytological smears was statistically significant $(\mathrm{p}<0.0001)$

\section{CONCLUSION}

We found that higher percentage of patients had Pleural Fluid. The utility of cell block method in cytodiagnosis of malignant effusions was significant in our study.

CB is superior to CS for diagnosis of malignant effusions and hence it should be used in adjunct to CS in difficult or suspected malignant cases for better yield.

We may concluded that Cell block technique is superior to conventional smear technique, especially for malignant effusions.
Table: Association between Nature Of Fluid : CELL BLOCK

\begin{tabular}{|c|c|c|c|c|c|c|}
\hline \multicolumn{5}{|c|}{ CELL BLOCK } & \multirow[b]{2}{*}{$\begin{array}{r}\text { Chi- } \\
\text { square } \\
\text { value }\end{array}$} & \multirow[b]{2}{*}{ p-value } \\
\hline $\begin{array}{r}\text { Nature Of } \\
\text { Fluid }\end{array}$ & Benign & Malignant & Suspicious & Total & & \\
\hline Benign & 67 & 2 & 0 & 69 & 99.3659 & $<0.00001$ \\
\hline Row \% & 97.1 & 2.9 & 0.0 & 100.0 & & \\
\hline $\mathrm{Col} \%$ & 100.0 & 6.3 & 0.0 & 69.0 & & \\
\hline Malignant & 0 & 22 & 0 & 22 & & \\
\hline Row \% & 0.0 & 100.0 & 0.0 & 100.0 & & \\
\hline $\mathrm{Col} \%$ & 0.0 & 68.8 & 0.0 & 22.0 & & \\
\hline Suspicious & 0 & 8 & 1 & 9 & & \\
\hline Row \% & 0.0 & 88.9 & 11.1 & 100.0 & & \\
\hline $\mathrm{Col} \%$ & 0.0 & 25.0 & 100.0 & 9.0 & & \\
\hline TOTAL & 67 & 32 & 1 & 100 & & \\
\hline Row \% & 67.0 & 32.0 & 1.0 & 100.0 & & \\
\hline $\mathrm{Col} \%$ & 100.0 & 100.0 & 100.0 & 100.0 & & \\
\hline
\end{tabular}

\section{REFERENCE}

1. Wojcik EM, Selvagi SM. Comparison of smears and $\mathrm{s}$ in the fine needle aspiration diagnosis of recurrent gynecologic malignancies. Acta Cytol. 1991;35:773-6.

2. Nathan NA, Narayan E, Smith MM, Horn MJ. Cytology-improved preparation and it efficacy in diagnostic cytology. Am J Clin Pathol 2000;114:599-606.

3. Dey S, Nag D, Nandi A, Bandyopadhyay R. Utility of cell block to detect malignancy in fluid cytology: Adjunct or necessity? Journal of cancer research and therapeutics. 2017 fluid cytology: Ad $13(3): 425$.

4. Sudha A, Korti P, Prabhala S, Deshpande AK. Cytologic analysis of body fluids with an emphasis on malignant effusions. Indian Journal of Pathology and Oncology. 2018 Jan;5(1):106-11.

5. Barui G, Talukdar M, Sarkar M. HOW ESSENTIAL IS CELL BLOCK PREPARATION IN EACH AND EVERY SPECIMEN OF BODY FLUID SENT FOR CYTOLOGY IN ADDITION TO CONVENTIONAL SMEAR-AN OBSERVATIONAL AND ANALYTICAL STUDY IN A TERTIARY CARE CENTRE. 2017 :Dec :4 :94:57545758 .

6. Kumavat PV, Kulkarni MP, Sulhyan KR. Cytological study of effusions. Indian Medical Gazette. 2013;306.

7. Shivakumarswamy U, Arakeri SU, Karigowdar MH, Yelikar BR. Diagnostic utility of the cell block method versus the conventional smear study in pleural fluid cytology. Journal of Cytology/Indian Academy of Cytologists. 2012 Jan;29(1):11.

8. Suri J, Gandotra V, Abrol D, Bhardwaj S. Analysis of cell block vs. conventional smear in fluid cytology. Journal of Evidence Based Medicine and Healthcare. 2015;2(39):6464-71.

9. Matreja SS, Malukani K, Nandedkar SS, Varma AV, Saxena A, Ajmera A. Comparison of efficacy of cell block versus conventional smear study in exudative fluids. Nigerian Postgraduate Medical Journal. 2017 Oct 1;24(4):245. 